\title{
Análisis estructural y de diversidad en los bosques de Abies de Jalisco, México
}

\section{Structural and diversity analysis of Abies forests from Jalisco, Mexico}

\author{
Ramón Cuevas-Guzmán ${ }^{凶}$, Edgar A. Cisneros-Lepe, Enrique J. Jardel-Peláez, Enrique V. Sánchez-Rodríguez, \\ Luis Guzmán-Hernández, Nora M. Núñez-López y Clotilde Rodríguez-Guerrero. \\ Instituto Manantlán de Ecología y Conservación de la Biodiversidad, Centro Universitario de la Costa Sur, Universidad de Guadalajara, 48900 Autlán \\ de Navarro, Jalisco, México. \\ \ruevas@cucsur.udg.mx
}

\begin{abstract}
Resumen. En 24 parcelas de 0.1 ha, distribuidas en 5 áreas del estado de Jalisco, se determinaron la estructura, composición florística y diversidad de los bosques de Abies, y sus atributos fueron comparados entre áreas. Se registraron 64 especies, 47 géneros y 35 familias. Asteraceae, Pinaceae y Fagaceae y los géneros Quercus, Pinus y Abies fueron los más ricos en especies. El 56\% de los individuos tuvo alturas entre 2 y $14 \mathrm{~m}$; las mayores se presentaron en Abies religiosa var. emarginata, A. guatemalensis var. jaliscana, Quercus xalapensis y A. religiosa var. religiosa. Los mayores valores de densidad, área basal, frecuencia y valor de importancia fueron para A. religiosa var. emarginata, A. religiosa var. religiosa, Pinus pseudostrobus y Podocarpus matudae. Los individuos de las especies presentaron una distribución diamétrica en forma de "J" invertida en las 5 zonas estudiadas, mientras que la riqueza y la diversidad de especies no mostraron diferencias estadísticas significativas entre las áreas. La similitud promedio entre las parcelas de las 5 áreas mostró diferencias estadísticas significativas para 4 de ellas. Aunque muy diferentes en su composición florística, los bosques de Abies de Jalisco resultaron similares en riqueza, diversidad y estructura. En las 5 áreas, las comunidades mostraron buena capacidad de recuperación pues en todos los estratos se presentaron individuos altos y árboles emergentes.
\end{abstract}

Palabras clave: composición florística, estructura, índice de Simpson, índice cuantitativo de Sørensen, oyamel.

\begin{abstract}
Structure, floristic composition and diversity in Abies forests were determined in twenty-four 0.1 ha plots in 5 areas in Jalisco State. The resulting attributes were compared between areas. Sixty four species, 47 genera and 35 families were recorded. The families Asteraceae, Pinaceae and Fagaceae, as well as the genera Quercus, Pinus and Abies had the highest species richness. More than half (56\%) of the individuals had a height ranging between 2 and $14 \mathrm{~m}$, with Abies religiosa var. emarginata, A. guatemalensis var. jaliscana, Quercus xalapensis and A. religiosa var. religiosa presenting the taller trees. The highest density values, basal area, frequency and importance values were for $A$. religiosa var. emarginata, A. religiosa var. religiosa, Pinus pseudostrobus y Podocarpus matudae. Individuals of the species presented an inverted "I"- shaped diameter distribution, while no statistical significant differences were observed for richness and species diversity in the 5 study areas. Average similarity between plots in the 5 areas presented significant differences in 4 of the plots. Despite being quite different in floristic composition, Abies forests in Jalisco were similar in structure, diversity and richness. The presence of tall individuals and emergent trees in all strata suggests a good regeneration capacity in the communities of the 5 areas studied.
\end{abstract}

Key words: floristic composition, structure, Simpson index, Sørensen quantitative index, fir.

\section{Introducción}

Los bosques de Abies en México presentan una distribución insular, producto de la historia geológica y ecológica a la que han estado sometidos a través del tiempo (Rzedowski, 1978). Se considera que cubren entre 320 y $500 \mathrm{~km}^{2}$ de la superficie de la República Mexicana (Manzanilla, 1974; Rzedowski, 1978), de los cuales se encuentran alrededor de 12120 ha en el estado de Jalisco,

Recibido: 23 octubre 2009; aceptado: 04 mayo 2011 lo que representa el $0.15 \%$ de la superficie de esta entidad federativa (PRODEFO, 1999). Las mayores extensiones de Abies se han registrado para las serranías que circundan el valle de México, las faldas de los volcanes con mayor altitud en el Eje Neovolcánico Transversal y algunas porciones de la sierra Madre del Sur (Rzedowski, 1978). Se les considera comunidades vegetales bajas en riqueza y diversidad de especies, y poco complejas estructuralmente (Manzanilla, 1974; Calvert y Lawton, 1993).

La estructura, composición florística, diversidad, distribución y extensión geográfica de los bosques de Abies han sido afectadas por los aprovechamientos forestales sin 
control, los incendios forestales frecuentes, la ganadería extensiva, la contaminación atmosférica, el crecimiento de centros de población y la conversión de zonas boscosas a terrenos de cultivo de avena, papa, maíz o pastizales, causando estos 2 últimos la eliminación de esta vegetación (Alvarado et al., 1991; Sánchez-Velásquez et al., 1991; López et al., 1998; Earle, 2002; Körner, 2002; UAAAN, 2002; Saavedra-Romero et al., 2003; Velásquez-Villatoro, 2004), y se ha sugerido que el cambio climático tendrá repercusiones sobre la distribución y extensión de los bosques de Abies (Fagre y Peterson, 2002). Como resultado del deterioro de estos bosques y la reducción que han experimentado sus poblaciones, varias especies mexicanas del género se encuentran actualmente catalogadas en alguna categoría de riesgo (SEMARNAT, 2010).

Los oyametales han despertado interés, por motivos diversos, como el color de su follaje o su distribución en las altas montañas cerca del límite superior de la vegetación arbórea; también por la utilidad de su madera, resinas y follaje, así como por el proceso de especiación al que ha estado sometido el grupo en diferentes refugios geográficos o el efecto potencial del cambio climático sobre esa comunidad vegetal.

Todo ello ha hecho que estos árboles sean estudiados con diversos enfoques, como el taxonómico, de distribución y de uso (Martínez, 1963; McVaugh, 1992; Nieto de Pascual-Pola et al., 1995); estructural, de diversidad y silvícola (Madrigal-Sánchez, 1967; Manzanilla, 1974; Sánchez-Velásquez et al., 1991; Ávila-Bello et al., 1994; Rendón, 1997; Villers-Ruiz et al., 1998; Jiménez, 2004; Encina-Domínguez et al., 2008), o bien, el efecto del fuego y la respuesta a variables ambientales (Ávila-Bello et al., 1994; Fulé y Covington, 1997; Sánchez-González y López-Mata, 2003).

En el estado de Jalisco hay pocas investigaciones que caractericen la composición florística, la estructura y la diversidad de los bosques de Abies, o sólo las hay para alguna localidad o abordando únicamente algunos de esos aspectos (Manzanilla, 1974; Figueroa-Rangel, 1991; Ramos-Herrera, 1991; Figueroa-Rangel y Moreno-Gómez, 1993). Por ello, en la presente investigación se analiza la composición florística, la estructura y la diversidad de los oyametales de 5 áreas del estado de Jalisco y se comparan entre sí.

\section{Materiales y métodos}

Área de estudio. Se hizo un muestreo dirigido a los bosques de Abies en el estado de Jalisco, para lo cual se seleccionaron mediante fotografía área y recorridos de campo 5 zonas donde se presenta esta comunidad vegetal: las sierras de Cacoma, Atenguillo, Manantlán, Cuale y el Nevado de Colima (Fig. 1). En cada zona de estudio se establecieron 5 parcelas en diferentes sitios, que fueran lugares conservados y más o menos homogéneos en topografía, pendiente y exposición, de acuerdo con un criterio prefijado. En cada área, las parcelas estuvieron separadas de 50 a $500 \mathrm{~m}$, con excepción de la sierra de Manantlán donde 2 parcelas se establecieron aproximadamente a $1.5 \mathrm{~km}$ de las 3 restantes, porque no fue posible contar con 5 unidades de muestreo a menor distancia. En la sierra de Cuale, por la disponibilidad de sitios con bosques de Abies, sólo fue posible establecer 4 unidades. Los datos de localización e información ambiental de las áreas y unidades de muestreo se presentan en el Cuadro 1.

Muestreo y obtención de datos de campo. En total se muestreó un área de 2.4 hectáreas de bosques de Abies, de las cuales, 0.5 correspondieron a la sierra de Cacoma, 0.5 al Nevado de Colima, 0.5 a la sierra de Manantlán, 0.4 a la sierra de Cuale y 0.5 a la sierra de Atenguillo (Fig. 1, Cuadro 1). En cada área, las parcelas midieron $60 \times 48$ $\mathrm{m}$, y cada una estuvo dividida en 20 subparcelas de $12 \times$ $12 \mathrm{~m}$. De estas últimas, 10 se seleccionaron de manera aleatoria; 5 a cada lado de una línea que dividió la parcela en 2 partes de $24 \times 60 \mathrm{~m}$. En cada subparcela seleccionada se colocó una estaca central, a partir de la cual se trazó un círculo de radio $=5.64 \mathrm{~m}$ para obtener un área de 100 $\mathrm{m}^{2}$ por subparcela, y en su conjunto de 0.1 ha por parcela (Curtis y McIntosh, 1951; Vázquez y Givnish, 1998; Cuevas-Guzmán, 2002; Cuevas-Guzmán et al., 2008). En cada círculo de $100 \mathrm{~m}^{2}$ se identificó, registró y midió el diámetro a la altura del pecho (dap) (a $1.3 \mathrm{~m}$ arriba del suelo) y la altura de cada una de las especies leñosas con diámetro $\geq 2.5 \mathrm{~cm}$. En cada parcela se registraron las coordenadas, la altitud y la pendiente. Se contaron por parcela, los árboles caídos y los muertos en pie, con dap $\geq 10 \mathrm{~cm}$, así como los tocones, considerando como tocones aquellos troncos cortados con fines maderables. La incidencia de incendios y el grado de pastoreo se evaluaron con los criterios recomendados por Olvera-Vargas et al. (1996) (Cuadro 1). Se recolectaron muestras de ejemplares botánicos para corroborar las identificaciones hechas en campo. Todo el material fue procesado y depositado en el herbario ZEA del Centro Universitario de la Costa Sur de la Universidad de Guadalajara.

Análisis de los datos. Para cada parcela se determinó la composición florística, el área basal, la densidad, la frecuencia y el valor de importancia, este último estimado como el promedio de los valores relativos de área basal, densidad y frecuencia multiplicado por 100 (Curtis y McIntosh, 1951; McCune y Mefford, 1999). La búsqueda de patrones en la estratificación vertical por parcela se hizo graficando los individuos de todas las especies en el eje de las abscisas $v s$. su altura en el eje de las ordenadas. 

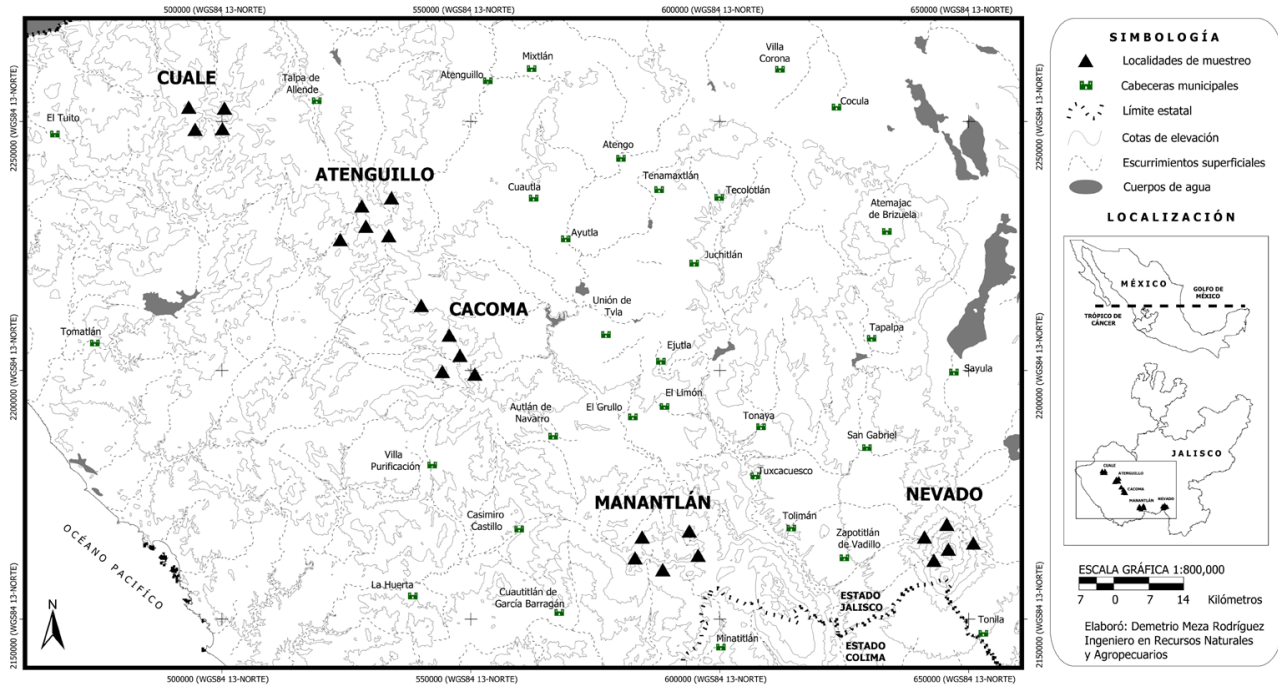

Figura 1. Localización de las áreas y unidades de muestreo de oyametales en el estado de Jalisco.

Cuadro 1. Información geográfica y ambiental de las áreas y unidades de muestreo en bosques de Abies de Jalisco, México

\begin{tabular}{|c|c|c|c|c|c|c|c|c|c|c|c|c|c|}
\hline Área & Parcela & $\begin{array}{l}\text { Altitud } \\
\text { (m snm) }\end{array}$ & Coordenadas & $\begin{array}{l}\text { Pen. } \\
(\%)\end{array}$ & Pedre. & Inc. & ** Past & $A C$ & $A M P$ & Tocones & $\begin{array}{l}\text { TMA } \\
\left({ }^{\circ} \mathrm{C}\right) \\
\end{array}$ & $\begin{array}{l}P M A \\
(\mathrm{~mm}) \\
\end{array}$ & Clima \\
\hline \multirow[t]{5}{*}{ Cacoma } & 1 & 2162 & $19^{\circ} 54^{\prime} 16^{\prime \prime} \mathrm{N}$ y $104^{\circ} 32^{\prime} 30.2^{\prime \prime} \mathrm{O}$ & 42 & 1 & 1 & 0 & 0 & 30 & 6 & 16-18 & $1500-2000$ & \multirow{5}{*}{$\begin{array}{c}\mathrm{A}) \mathrm{C}\left(\mathrm{w}_{2}\right) \\
(\mathrm{w}) \mathrm{y} \\
\mathrm{C}\left(\mathrm{w}_{2}\right) \\
(\mathrm{w})\end{array}$} \\
\hline & 2 & 2127 & $19^{\circ} 54^{\prime} 18.2^{\prime \prime} \mathrm{N}$ y $104^{\circ} 32^{\prime} 25.3^{\prime \prime} \mathrm{O}$ & 14 & 1 & 1 & 1 & 1 & 7 & 4 & & & \\
\hline & 3 & 2090 & $19^{\circ} 54^{\prime} 30.4^{\prime \prime} \mathrm{N}$ y $104^{\circ} 32^{\prime} 16.5^{\prime \prime} \mathrm{O}$ & 21 & 1 & 0 & 1 & 2 & 5 & 7 & & & \\
\hline & 4 & 2100 & $19^{\circ} 55^{\prime} 59.2^{\prime \prime} \mathrm{N}$ y $104^{\circ} 32^{\prime} 32.3^{\prime \prime} \mathrm{O}$ & 65 & 2 & 1 & 3 & 1 & 1 & 4 & & & \\
\hline & 5 & 2370 & $20^{\circ} 00^{\prime} 58.1^{\prime \prime} \mathrm{N}$ y $104^{\circ} 36^{\prime} 28.9^{\prime \prime} \mathrm{O}$ & 22 & 1 & 1 & 4 & 6 & 1 & 4 & & & \\
\hline \multirow[t]{5}{*}{ Nevado } & 6 & 2906 & $19^{\circ} 36^{\prime} 5.1^{\prime \prime} \mathrm{N}$ y $103^{\circ} 38^{\prime} 13.6^{\prime \prime} \mathrm{O}$ & 8 & 1 & 0 & 1 & 1 & 1 & 9 & $8-12$ & 1200 & \multirow{5}{*}{$\begin{array}{l}\mathrm{C}\left(\mathrm{w}_{2}\right) \mathrm{y} \\
\mathrm{C}(\mathrm{E})\left(\mathrm{w}_{2}\right)\end{array}$} \\
\hline & 7 & 2980 & $19^{\circ} 35^{\prime} 57.2^{\prime \prime} \mathrm{N}$ y $103^{\circ} 38^{\prime} 11.5^{\prime \prime} \mathrm{O}$ & 42 & 1 & 0 & 1 & 3 & 3 & 21 & & & \\
\hline & 8 & 3015 & $19^{\circ} 35^{\prime} 54.4^{\prime \prime} \mathrm{N}$ y $103^{\circ} 38^{\prime} 11.0^{\prime \prime} \mathrm{O}$ & 48 & 1 & 0 & 1 & 0 & 14 & 9 & & & \\
\hline & 9 & 2900 & $19^{\circ} 36^{\prime} 27.4^{\prime \prime} \mathrm{N}$ y $103^{\circ} 38^{\prime} 14.0^{\prime \prime} \mathrm{O}$ & 17 & 1 & 0 & 1 & 2 & 2 & 12 & & & \\
\hline & 10 & 2930 & $19^{\circ} 36^{\prime} 19.8^{\prime \prime} \mathrm{N}$ y $103^{\circ} 38^{\prime} 2.1^{\prime \prime} \mathrm{O}$ & 28 & 1 & 0 & 1 & 1 & 4 & 11 & & & \\
\hline \multirow[t]{5}{*}{ Manantlán } & 11 & 2750 & $19^{\circ} 33^{\prime} 24^{\prime \prime} \mathrm{N}$ y $104^{\circ} 6^{\prime} 8.4^{\prime \prime} \mathrm{O}$ & 8 & 1 & 2 & 4 & 1 & 11 & 9 & $16-18$ & 1200 & \multirow{5}{*}{$\begin{array}{c}(\mathrm{A}) \mathrm{C}\left(\mathrm{w}_{2}\right) \\
(\mathrm{w}) \mathrm{y} \\
\mathrm{C}\left(\mathrm{w}_{2}\right) \\
(\mathrm{w})\end{array}$} \\
\hline & 12 & 2700 & $19^{\circ} 33^{\prime} 48.3^{\prime \prime} \mathrm{N}$ y $104^{\circ} 6^{\prime} 31.9^{\prime \prime} \mathrm{O}$ & 15 & 1 & 3 & 2 & 1 & 13 & 9 & & & \\
\hline & 13 & 2700 & $19^{\circ} 33^{\prime} 30.0^{\prime \prime} \mathrm{N}$ y $104^{\circ} 07^{\prime} 38.0^{\prime \prime} \mathrm{O}$ & 17 & 1 & 4 & 4 & 12 & 11 & 0 & & & \\
\hline & 14 & 2450 & $19^{\circ} 33^{\prime} 40.7^{\prime \prime} \mathrm{N}$ y $104^{\circ} 11^{\prime} 8.1^{\prime \prime} \mathrm{O}$ & 21 & 1 & 2 & 1 & 0 & 5 & 1 & & & \\
\hline & 15 & 2450 & $19^{\circ} 33^{\prime} 37.0^{\prime \prime} \mathrm{N}$ y $104^{\circ} 11^{\prime} 12.0^{\prime \prime} \mathrm{O}$ & 22 & 1 & 1 & 1 & 2 & 3 & 2 & & & \\
\hline \multirow[t]{4}{*}{ Cuale } & 16 & 2435 & $20^{\circ} 21^{\prime} 12.6^{\prime \prime} \mathrm{N}$ y $105^{\circ} 00^{\prime} 23.9^{\prime \prime} \mathrm{O}$ & 57 & 4 & 3 & 1 & 4 & 1 & 6 & $16-20$ & $1500-2000$ & \multirow{4}{*}{$\begin{array}{c}(\mathrm{A}) \mathrm{C}\left(\mathrm{w}_{2}\right) \\
(\mathrm{w}) \mathrm{y} \\
\mathrm{C}\left(\mathrm{w}_{2}\right) \\
(\mathrm{w})\end{array}$} \\
\hline & 17 & 2435 & $20^{\circ} 21^{\prime} 14.0^{\prime \prime} \mathrm{N}$ y $105^{\circ} 00^{\prime} 24.6^{\prime \prime} \mathrm{O}$ & 36 & 5 & 2 & 4 & 5 & 3 & 0 & & & \\
\hline & 18 & 2434 & $20^{\circ} 21^{\prime} 15.6^{\prime \prime} \mathrm{N}$ y $105^{\circ} 00^{\prime} 18.0^{\prime \prime} \mathrm{O}$ & 57 & 4 & 2 & 4 & 2 & 7 & 0 & & & \\
\hline & 19 & 2160 & $20^{\circ} 22^{\prime} 4.1^{\prime \prime} \mathrm{N}$ y $105^{\circ} 1^{\prime} 59.8^{\prime \prime} \mathrm{O}$ & 64 & 4 & 3 & 3 & 1 & 10 & 1 & & & \\
\hline \multirow[t]{5}{*}{ Atenguillo } & 20 & 2162 & $20^{\circ} 11^{\prime} 23.5^{\prime \prime} \mathrm{N}$ y $104^{\circ} 42^{\prime} 28.1^{\prime \prime} \mathrm{O}$ & 41 & 1 & 0 & 2 & 1 & 5 & 6 & $16-18$ & $1200-1500$ & \multirow{5}{*}{$\begin{array}{c}(\mathrm{A}) \mathrm{C}\left(\mathrm{w}_{2}\right) \\
(\mathrm{w}) \mathrm{y} \\
\mathrm{C}\left(\mathrm{w}_{2}\right) \\
(\mathrm{w})\end{array}$} \\
\hline & 21 & 2210 & $20^{\circ} 10^{\prime} 20.4^{\prime \prime} \mathrm{N}$ y $104^{\circ} 42^{\prime} 0.6^{\prime \prime} \mathrm{O}$ & 11 & 1 & 1 & 1 & 0 & 28 & 10 & & & \\
\hline & 22 & 2279 & $20^{\circ} 10^{\prime} 22.0^{\prime \prime} \mathrm{N}$ y $104^{\circ} 41^{\prime} 54.5^{\prime \prime} \mathrm{O}$ & 19 & 1 & 1 & 1 & 0 & 5 & 16 & & & \\
\hline & 23 & 2200 & $20^{\circ} 10^{\prime} 38.8^{\prime \prime} \mathrm{N}$ y $104^{\circ} 41^{\prime} 54.8^{\prime \prime} \mathrm{O}$ & 17 & 1 & 1 & 1 & 1 & 16 & 9 & & & \\
\hline & 24 & 2280 & $20^{\circ} 10^{\prime} 16.8^{\prime \prime} \mathrm{N}$ y $104^{\circ} 41^{\prime} 42.5^{\prime \prime} \mathrm{O}$ & 22 & 1 & 1 & 1 & 0 & 21 & 12 & & & \\
\hline
\end{tabular}

Nevado, Nevado de Colima; Exp., exposición; Pen., pendiente; Pedre., pedregosidad; Inc., incendios; Past., pastoreo; AC, árboles caídos; AMP, árboles muertos en pie. de Incendios: 0, nulo; 1, ligero; 2, moderado; 3, fuerte; 4, severo (según criterios de Olvera et al. [1996] para evaluar la incidencia). Pastoreo: 0, nulo; 1, ligero; 2, moderado; 3, fuerte; 4, severo. Pedregosidad: 1, 0-20\%; 2, 21-40\%; 3, 41-60\%; 4, 61-80\%; 5, > 80\%. TMA, temperatura media anual; PMA = precipitación media anual. 
Esto permitió dividir en 5 estratos: I (2-7 $\mathrm{m}$ de altura), II (8-14 m), III (15-25 m), IV (26-30 m), y V (>30 m). Se obtuvo la altura promedio del dosel como la sumatoria de la altura de todos los individuos de una parcela, un área o las 2.4 ha de bosque muestreado, dividido entre el número total de individuos, excluyéndose del análisis las especies de bejucos. Se obtuvo la riqueza de especies, géneros, y familias, y el índice de Simpson, considerado como uno de los más apropiados cuando la dominancia de la comunidad corresponde a una o pocas especies (Magurran, 2004). La diversidad beta se calculó con el índice cuantitativo de Sørensen (Magurran, 2004). Empleando los datos estructurales de composición florística y diversidad se hizo una comparación dentro y entre áreas. Para la comparación de la riqueza de familias, géneros y especies y el índice de Simpson, se utilizaron 4 parcelas de cada área para contar con las mismas unidades de muestreo y de superficie, y se realizó un análisis de varianza. Para el análisis de los atributos estructurales y la similitud promedio entre parcelas y áreas, se consideraron todas las unidades de muestreo. Se aplicó un análisis de varianza mediante el procedimiento GLM con la prueba del rango estudentizado de Tukey y con una $\alpha=0.05$. Ambos procedimientos se corrieron con el programa SAS versión 8.0 (SAS, 1999).

\section{Resultados}

Composición florística. En las 24 parcelas se registraron 64 especies, 47 géneros y 35 familias. Las familias con más especies fueron Asteraceae, Pinaceae, Fagaceae, Betulaceae, Lauraceae y Solanaceae y los géneros más diversos fueron Quercus, Pinus, Abies y Eupatorium (Cuadro 2). El número de familias, géneros y especies varió de 9-21, 12-24 y 14-28 por área, registrándose los valores más bajos para el Nevado de Colima y los mayores para Cacoma y Manantlán, aunque es de considerar que en Cuale únicamente se registró lo de 4 parcelas (Cuadro 3). Las familias más ricas por área fueron Pinaceae, Asteraceae y Fagaceae, pero en Manantlán Betulaceae se colocó también entre las primeras. Los géneros más diversos por área fueron Quercus, Pinus y Senecio, aunque en Manantlán Clethra sobresalió por su número de especies (Cuadro 2). En general, las familias y los géneros más diversos mostraron coincidencia entre las áreas (Cuadro 2 y 3). Se registraron 42 especies de árboles (66\%), 8 de arbusto-árboles (12\%), 11 de arbustos (17\%) y 3 de bejucos (5\%) (Cuadro 2).

Estructura vertical. De los 5 estratos reconocidos en las 2.4 ha de bosque muestreado, el que presentó el mayor porcentaje de individuos fue el estrato I con $34 \%$, y el que tuvo menos fue el IV con 7\% (Cuadro 3). El promedio del dosel osciló entre 14 y 15 m de altura. Más de la mitad (54\%) de los individuos presentaron alturas entre 2 y 14 m (Cuadro 3). Las especies con mayor altura fueron Abies religiosa var. emarginata con $51 \mathrm{~m}$, A. guatemalensis var. jaliscana con $47 \mathrm{~m}$, Quercus xalapensis con $47 \mathrm{~m}$, A. religiosa var. religiosa con $43 \mathrm{~m}, Q$. candicans con $43 \mathrm{~m}, Q$. laurina con $40 \mathrm{~m}$, Clethra fragrans con $38 \mathrm{~m}, Q$. scytophylla con $38 \mathrm{~m}$ y $Q$. martinezii con $37 \mathrm{~m}$.

En las 5 áreas estudiadas, $A$. religiosa var. emarginata, A. religiosa var. religiosa, A. guatemalensis var. jaliscana, Pinus pseudostrobus, Q. laurina, Q. scytophylla y Q. martinezii presentaron individuos en todos los estratos, aunque en estado maduro fueron exclusivos de los estratos III al V. Desmodium sumichrastii, Rumfordia floribunda, Senecio angulifolius, Euphorbia schlechtendalii, Cestrum terminale, Eupatorium mairetianum, S. barba-johannis y Leandra subseriata fueron especies exclusivas del estrato I. Podocarpus matudae, Arbutus xalapensis, Cleyera integrifolia, Clethra fragrans, Cornus disciflora, Ostrya virginiana, Persea hintonii, Pinus douglasiana, Symplocos citrea y Ternstroemia lineata subsp. lineata presentaron individuos desde el estrato I al III. Eupatorium mairetianum, Lippia umbellata y Xylosma flexuosa tuvieron individuos en los estratos I y II (Cuadro 4).

En las 5 áreas boscosas, el mayor porcentaje de individuos se registró para los estratos I y II, donde en promedio se encontró entre el 47.9 y $59.2 \%$ de los individuos, mientras que los estratos con menos individuos fueron el IV y V (Cuadro 3).

En las 5 áreas se registraron especies de los géneros Abies, Pinus, Quercus como las de mayor altura, acompañadas de otras especies latifoliadas, como Clethra fragrans, Cornus disciflora, Magnolia iltisiana, Buddleja cordata e Ilex brandegeana (Cuadro 4).

Estructura cuantitativa. En total se registraron 1847 individuos de plantas leñosas con diámetro $\geq 2.5 \mathrm{~cm}$ en las 2.4 ha. Las mayores densidades, áreas basales, frecuencias y valores de importancia fueron las de A. religiosa var. emarginata, A. religiosa var. religiosa, P. pseudostrobus, Podocarpus matudae, Q. laurina, Symplocos citrea, $Q$. scytophylla y A. guatemalensis var. jaliscana. Las especies que presentan los valores más bajos para esos atributos fueron Celastrus pringlei, Cinnamomun pachypodum, Eupatorium areolare, E. lasioneuron, Fraxinus uhdei y Rhamnus hintonii, entre otras (Cuadro 4).

El área basal y la densidad por hectárea variaron de 48.5 a $60.5 \mathrm{~m}^{2}$ y de 608 a 954 individuos, registrándose los menores valores en el Nevado de Colima y los mayores en Atenguillo (Cuadro 4). Las mayores áreas basales y densidades se registraron en las especies de Abies, Pinus y Quercus en las 5 áreas estudiadas, aunque cada especie con alguna particularidad (Cuadro 4). En Cacoma, sobresalieron Euphorbia schlechtendalii y Symplocos citrea por sus altas densidades, aunque mostraron valores bajos de área 


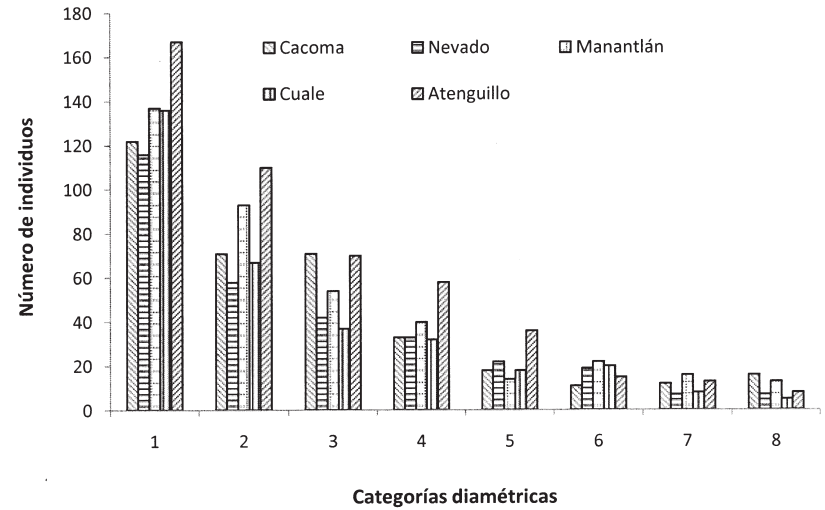

Figura 2. Distribución de las categorías diamétricas en las cinco áreas. $1=2.5-10.5 \mathrm{~cm} ; 2=10.6-20.5 \mathrm{~cm} ; 3=20.6-30.5 \mathrm{~cm} ; 4=$ $30.6-40.5 \mathrm{~cm} ; 5=40.6-50.5 \mathrm{~cm} ; 6=50.6-60.5 \mathrm{~cm} ; 7=60.6-70.5$ $\mathrm{cm} ; 8>70.5 \mathrm{~cm}$. Nevado= Nevado de Colima. basal, patrón presentado por votras especies arbustivas como Senecio angulifolius en Manantlán y Desmodium sumichrastii en Cuale (Cuadro 4). Entre 3 y 5 especies en cada área de estudio comprendieron del 62 al 85\% del valor de importancia y las especies de Abies en Cacoma, el Nevado de Colima y Atenguillo registraron más del 50\% del valor de importancia en cada área. El valor de importancia de Abies en Cuale y Manantlán varió del 24.7 al 29\% (Cuadro 4). En Cuale sobresalió el valor de importancia de Pinus strobiformis y en Atenguillo el de Podocarpus matudae, registrándose estas especies como exclusivas de cada una de las áreas señaladas (Cuadro 4). No se encontraron diferencias significativas $(\alpha=0.05)$ para el área basal y la densidad, entre las áreas y las parcelas dentro de cada área.

En las 5 áreas se observó un comportamiento muy similar respecto a la distribución de las categorías diamétricas,

Cuadro 2. Catálogo de taxones registrados en las unidades de muestreo de las 5 áreas en los bosques de Abies de Jalisco, México

\begin{tabular}{|c|c|c|c|c|c|c|c|}
\hline Nombre cientifico & Acrónimo & Biotipo & Cacoma & Nevado & Manantlán & Cuale & Atenguillo \\
\hline ANACARDIACEAE & & & & & & & \\
\hline $\begin{array}{l}\text { Toxicodendron radicans } \mathrm{L} \text {. Kuntze } \\
\text { AQUIFOLIACEAE }\end{array}$ & Toxrad & Bejuco & 0 & 0 & 0 & 0 & 1 \\
\hline $\begin{array}{l}\text { Ilex brandegeana Loes. } \\
\text { ASTERACEAE }\end{array}$ & Ilebra & Árbol & 1 & 0 & 0 & 0 & 1 \\
\hline Eupatorium areolare DC. & Eupare & Arbusto-árbol & 1 & 0 & 0 & 0 & 0 \\
\hline E. lasioneuron Hook et Arn. & Euplas & Arbusto-árbol & 0 & 0 & 0 & 1 & 0 \\
\hline E. mairetianum DC. & Eupmai & Arbusto-árbol & 0 & 1 & 1 & 0 & 1 \\
\hline Perymenium alticola McVaugh & Peralt & Arbusto-árbol & 0 & 0 & 0 & 1 & 0 \\
\hline Podachaenium eminens (Lag.) Sch. Bip. & Podemi & Árbol & 0 & 0 & 1 & 0 & 0 \\
\hline Rumfordia floribunda DC. & Rumflo & Arbusto & 1 & 1 & 1 & 1 & 1 \\
\hline Senecio angulifolius DC. & Senang & Arbusto & 0 & 1 & 1 & 1 & 0 \\
\hline $\begin{array}{l}\text { S. barba-johannis DC. } \\
\text { BETULACEAE }\end{array}$ & Senbar & Arbusto & 0 & 1 & 1 & 0 & 0 \\
\hline Alnus jorullensis Kunth & Alnjor & Árbol & 0 & 0 & 1 & 0 & 1 \\
\hline Carpinus tropicalis (J.D. Sm.) Lundell & Cartro & Árbol & 0 & 0 & 1 & 0 & 0 \\
\hline $\begin{array}{l}\text { Ostrya virginiana (Mill.) K. Koch } \\
\text { BUDDLEJACEAE }\end{array}$ & Ostvir & Árbol & 0 & 0 & 1 & 1 & 1 \\
\hline $\begin{array}{l}\text { Buddleja cordata Kunth } \\
\text { BUXACEAE }\end{array}$ & Budcor & Árbol & 0 & 1 & 1 & 0 & 0 \\
\hline Sarcococca conzattii Standl. & Sarcon & Arbusto & 1 & 0 & 0 & 0 & 0 \\
\hline $\begin{array}{l}\text { CAESALPINIACEAE } \\
\text { Senna multifoliolata (P. G. Wilson) Irwin y } \\
\text { Barneby } \\
\text { CAPRIFOLIACEAE }\end{array}$ & Senmul & Arbusto & 0 & 0 & 0 & 0 & 1 \\
\hline $\begin{array}{l}\text { Viburnum hartwegii Benth. } \\
\text { CELASTRACEAE }\end{array}$ & Vibhar & Árbol & 0 & 1 & 0 & 0 & 0 \\
\hline $\begin{array}{l}\text { Celastrus pringlei } \text { Rose } \\
\text { CLETHRACEAE }\end{array}$ & Celpri & Bejuco & 1 & 0 & 0 & 0 & 0 \\
\hline Clethra hartwegii Britton & Clehar & Árbol & 1 & 0 & 1 & 0 & 1 \\
\hline $\begin{array}{l}\text { C. fragrans L.M. González y R. Ramírez } \\
\text { CORNACEAE }\end{array}$ & Clefra & Árbol & 1 & 0 & 1 & 1 & 0 \\
\hline $\begin{array}{l}\text { Cornus disciflora Moc. y Sessé ex DC. } \\
\text { ERICACEAE }\end{array}$ & Cordis & Árbol & 1 & 1 & 1 & 0 & 0 \\
\hline
\end{tabular}


Cuadro 2. Continúa

\begin{tabular}{|c|c|c|c|c|c|c|c|}
\hline Nombre cientifico & Acrónimo & Biotipo & Cacoma & Nevado & Manantlán & Cuale & Atenguillo \\
\hline $\begin{array}{l}\text { Arbutus xalapensis Kunth } \\
\text { EUPHORBIACEAE }\end{array}$ & Arbxal & Árbol & 1 & 0 & 1 & 1 & 1 \\
\hline $\begin{array}{l}\text { Euphorbia schlechtendalii Boiss. } \\
\text { FABACEAE }\end{array}$ & Eupsch & Arbusto-árbol & 1 & 0 & 0 & 0 & 0 \\
\hline Desmodium sumichrastii (Schindl.) Standl. & Dessum & Arbusto & 0 & 0 & 0 & 1 & \\
\hline $\begin{array}{l}\text { Lupinus stipulatus J. Agardh } \\
\text { FAGACEAE }\end{array}$ & Lupsti & Arbusto & 0 & 1 & 0 & 0 & 0 \\
\hline Quercus candicans Née & Quecan & Árbol & 1 & 0 & 0 & 0 & 1 \\
\hline Q. laurina Humb. y Bonpl. & Quelau & Árbol & 1 & 1 & 1 & 1 & 0 \\
\hline Q. martinezii C. H. Muller & Quemar & Árbol & 1 & 0 & 0 & 0 & 1 \\
\hline Q. obtusata Humb. y Bonpl. & Queobt & Árbol & 0 & 0 & 0 & 0 & 1 \\
\hline Q. scytophylla Liebm. & Quescy & Árbol & 0 & 0 & 0 & 1 & 0 \\
\hline $\begin{array}{l}\text { Q. xalapensis Humb. y Bonpl. } \\
\text { FLACOURTIACEAE }\end{array}$ & Quexal & Árbol & 0 & 0 & 1 & 0 & 0 \\
\hline $\begin{array}{l}\text { Xylosma flexuosa (Kunth) Hemsl. } \\
\text { GARRYACEAE }\end{array}$ & Xylfle & Arbusto-árbol & 1 & 0 & 0 & 0 & 1 \\
\hline $\begin{array}{l}\text { Garrya laurifolia Hartweg ex Benth. } \\
\text { LAMIACEAE }\end{array}$ & Garlau & Árbol & 0 & 0 & 0 & 1 & 0 \\
\hline $\begin{array}{l}\text { Salvia mexicana } \mathrm{L} . \\
\text { LAURACEAE }\end{array}$ & Salmex & Arbusto & 0 & 0 & 1 & 0 & 0 \\
\hline Cinnamomum pachypodum (Nees) Kosterm. & Cinpac & Árbol & 0 & 0 & 1 & 0 & 0 \\
\hline Litsea glaucescens Kunth & Litgla & Arbusto-árbol & 0 & 0 & 0 & 1 & 0 \\
\hline $\begin{array}{l}\text { Persea hintonii C.K. Allen } \\
\text { MAGNOLIACEAE }\end{array}$ & Perhin & Árbol & 1 & 0 & 0 & 0 & 1 \\
\hline $\begin{array}{l}\text { Magnolia iltisiana A. Vázquez } \\
\text { MELASTOMATACEAE }\end{array}$ & Magilt & Árbol & 1 & 0 & 0 & 0 & 0 \\
\hline $\begin{array}{l}\text { Leandra subseriata (Naudin) Cogn. } \\
\text { OLEACEAE }\end{array}$ & Leasub & Arbusto & 1 & 0 & 0 & 0 & 0 \\
\hline $\begin{array}{l}\text { Fraxinus uhdei (Wenz.) Lingelsh. } \\
\text { ONAGRACEAE }\end{array}$ & Frauhd & Árbol & 1 & 0 & 0 & 0 & 0 \\
\hline $\begin{array}{l}\text { Fuchsia encliandra } \text { Steud. } \\
\text { PINACEAE }\end{array}$ & Fucenc & Arbusto & 0 & 0 & 0 & 1 & 1 \\
\hline $\begin{array}{l}\text { Abies guatemalensis Rehder var. jaliscana } \\
\text { Martínez }\end{array}$ & Abiguj & Árbol & 0 & 0 & 0 & 1 & 0 \\
\hline $\begin{array}{l}\text { A. religiosa (Kunth) Schltdl. y Cham. var. } \\
\text { emarginata Loock et Martínez ex Martínez }\end{array}$ & Abirem & Árbol & 1 & 0 & 1 & 0 & 1 \\
\hline $\begin{array}{l}\text { A. religiosa (Kunth) Schltdl. y Cham. var. } \\
\text { religiosa }\end{array}$ & Abirer & Árbol & 0 & 1 & 1 & 0 & 0 \\
\hline Pinus devoniana Lindl. & Pindev & Árbol & 1 & 0 & 0 & 0 & 0 \\
\hline P. douglasiana Martínez & Pindou & Árbol & 1 & 1 & 0 & 0 & 1 \\
\hline P. herrerae Martínez & Pinher & Árbol & 0 & 0 & 0 & 1 & 0 \\
\hline P. pseudostrobus Lindl. & Pinpse & Árbol & 0 & 1 & 1 & 1 & 1 \\
\hline $\begin{array}{l}\text { P. strobiformis Engelm. } \\
\text { PODOCARPACEAE }\end{array}$ & Pinstr & Árbol & 0 & 0 & 0 & 1 & 0 \\
\hline $\begin{array}{l}\text { Podocarpus matudae Lundell } \\
\text { RHAMNACEAE }\end{array}$ & Podmat & Árbol & 0 & 0 & 0 & 0 & 1 \\
\hline $\begin{array}{l}\text { Rhamnus hintonii M. C. Johnst. y L. A. } \\
\text { Johnst. } \\
\text { SABIACEAE }\end{array}$ & Rhahin & Árbol & 1 & 0 & 0 & 0 & 0 \\
\hline $\begin{array}{l}\text { Meliosma dentata (Liebm.) Urb. } \\
\text { SALICACEAE }\end{array}$ & Melden & Árbol & 1 & 0 & 1 & 0 & 0 \\
\hline $\begin{array}{l}\text { Salix paradoxa Kunth } \\
\text { SOLANACEAE }\end{array}$ & Salpar & Árbol & 0 & 1 & 0 & 0 & 0 \\
\hline Cestrum terminale Francey & Cester & Arbusto-árbol & 0 & 1 & 1 & 0 & 1 \\
\hline
\end{tabular}


Cuadro 2. Continúa

\begin{tabular}{|c|c|c|c|c|c|c|c|}
\hline Nombre cientifico & Acrónimo & Biotipo & Cacoma & Nevado & Manantlán & Cuale & Atenguillo \\
\hline Solanum brevipedicellatum Roe & Solbre & Árbol & 0 & 0 & 1 & 0 & 0 \\
\hline $\begin{array}{l}\text { S. chrysotrichum Schltdl. } \\
\text { STYRACACEAE }\end{array}$ & Solchr & Arbusto & 1 & 0 & 0 & 0 & 0 \\
\hline Styrax argenteus C. Presl. & Styarg & Árbol & 0 & 0 & 1 & 0 & 0 \\
\hline $\begin{array}{l}\text { S. ramirezii Greenm. } \\
\text { SYMPLOCACEAE }\end{array}$ & Styram & Árbol & 0 & 0 & 0 & 1 & 0 \\
\hline $\begin{array}{l}\text { Symplocos citrea Lex. } \\
\text { THEACEAE }\end{array}$ & Symcit & Árbol & 1 & 0 & 1 & 1 & 1 \\
\hline Cleyera integrifolia (Benth.) Choisy & Cleint & Árbol & 1 & 0 & 1 & 0 & 1 \\
\hline $\begin{array}{l}\text { Ternstroemia lineata DC. subsp. lineada } \\
\text { TILIACEAE }\end{array}$ & Terlin & Árbol & 1 & 0 & 1 & 1 & 0 \\
\hline $\begin{array}{l}\text { Tilia americana L. var. mexicana (Schltdl.) } \\
\text { Hardin } \\
\text { VERBENACEAE }\end{array}$ & Tilame & Árbol & 0 & 0 & 0 & 1 & 0 \\
\hline $\begin{array}{l}\text { Lippia umbellata Cav. } \\
\text { VITACEAE }\end{array}$ & Lipumb & Árbol & 0 & 0 & 1 & 1 & 1 \\
\hline Vitis blancoi Munson & Vitbla & Bejuco & 1 & 0 & 0 & 0 & 1 \\
\hline
\end{tabular}

Nevado, Nevado de Colima; 0, ausente; 1, presente.

Cuadro 3. Riqueza, estructura y diversidad por parcela de 0.1 ha y por área, incluyendo los promedios por parcela,en los bosques de Abies de Jalisco, México

\begin{tabular}{|c|c|c|c|c|c|c|c|c|c|c|c|}
\hline \multirow[t]{2}{*}{ Parcela } & \multirow[t]{2}{*}{ Especies } & \multirow[t]{2}{*}{ Géneros } & \multirow[t]{2}{*}{ Familias } & \multicolumn{5}{|c|}{$\%$ de individuos en los estratos verticales } & \multirow{2}{*}{$A B\left(m^{2} 0.1 h a^{-1}\right)$} & \multirow[t]{2}{*}{$D$ (ind. $0.1 h a^{-1}$ ) } & \multirow[t]{2}{*}{ Simpson } \\
\hline & & & & I & II & III & IV & V & & & \\
\hline 1 & 9 & 8 & 7 & 16 & 36.8 & 47.2 & 0 & 0 & 4.852 & 106 & 1.41 \\
\hline 2 & 9 & 9 & 8 & 11 & 29.7 & 52.7 & 3.3 & 3.3 & 5.446 & 91 & 2.53 \\
\hline 3 & 16 & 15 & 14 & 31.8 & 6.1 & 40.9 & 12.1 & 9.1 & 6.384 & 67 & 2.94 \\
\hline 4 & 10 & 9 & 9 & 57.4 & 25 & 5.9 & 0 & 11.8 & 5.582 & 69 & 5.7 \\
\hline 5 & 5 & 5 & 4 & 4.8 & 33.3 & 42.9 & 0 & 19 & 5.176 & 21 & 1.68 \\
\hline Cacoma & 28 & 24 & 21 & 24.2 & 26.2 & 37.9 & 3.1 & 8.6 & 5.488 & 70.8 & 2.8 \\
\hline 6 & 7 & 7 & 6 & 31.3 & 25 & 25 & 8.3 & 10.4 & 4.850 & 48 & 3.02 \\
\hline 7 & 7 & 6 & 4 & 63.3 & 32.9 & 2.5 & 1.3 & 0 & 2.124 & 79 & 1.38 \\
\hline 8 & 4 & 3 & 2 & 0 & 31.7 & 41.5 & 17.1 & 9.8 & 7.985 & 41 & 1.5 \\
\hline 9 & 9 & 9 & 7 & 53.1 & 10.9 & 12.5 & 20.3 & 3.1 & 4.366 & 64 & 2.87 \\
\hline 10 & 6 & 6 & 5 & 29.2 & 12.5 & 34.7 & 6.9 & 16.7 & 4.940 & 72 & 1.85 \\
\hline Nevado & 14 & 12 & 9 & 35.4 & 22.6 & 23.2 & 10.8 & 8 & 4.853 & 60.8 & 2.1 \\
\hline 11 & 6 & 6 & 5 & 21.6 & 53.6 & 19.6 & 4.1 & 1 & 5.655 & 97 & 2.28 \\
\hline 12 & 5 & 5 & 4 & 15.5 & 17.2 & 32.8 & 25.9 & 8.6 & 7.200 & 58 & 2.24 \\
\hline 13 & 6 & 6 & 5 & 23.3 & 45.6 & 27.8 & 2.2 & 1.1 & 4.337 & 90 & 2.75 \\
\hline 14 & 14 & 13 & 11 & 39.7 & 5.2 & 24.1 & 12.1 & 19 & 8.172 & 58 & 6.98 \\
\hline 15 & 20 & 19 & 15 & 66.3 & 8.1 & 15.1 & 0 & 10.5 & 4.192 & 86 & 10.81 \\
\hline Manantlán & 28 & 24 & 16 & 33.3 & 25.9 & 23.9 & 8.9 & 8 & 5.912 & 77.8 & 5 \\
\hline 16 & 9 & 9 & 6 & 33.3 & 9.3 & 38.9 & 11.1 & 7.4 & 4.555 & 54 & 4.66 \\
\hline 17 & 10 & 9 & 9 & 34.9 & 14.3 & 20.6 & 3.2 & 27 & 5.379 & 63 & 5.6 \\
\hline
\end{tabular}


Cuadro 3. Continúa

\begin{tabular}{|c|c|c|c|c|c|c|c|c|c|c|c|}
\hline \multirow[t]{2}{*}{ Parcela } & \multirow[t]{2}{*}{ Especies } & \multirow[t]{2}{*}{ Géneros } & \multirow[t]{2}{*}{ Familias } & \multicolumn{5}{|c|}{$\%$ de individuos en los estratos verticales } & \multirow[t]{2}{*}{$A B\left(m^{2} 0.1 h a^{-1}\right)$} & \multirow[t]{2}{*}{$D$ (ind. $\left.0.1 h a^{-1}\right)$} & \multirow[t]{2}{*}{ Simpson } \\
\hline & & & & I & II & III & IV & V & & & \\
\hline 18 & 14 & 13 & 10 & 67.4 & 14.1 & 4.3 & 0 & 14.1 & 6.111 & 92 & 5.19 \\
\hline 19 & 9 & 7 & 6 & 22.8 & 25.4 & 38.6 & 10.5 & 2.6 & 4.142 & 114 & 4.4 \\
\hline Cuale & 22 & 19 & 15 & 39.6 & 15.8 & 25.6 & 6.2 & 12.8 & 5.047 & 80.8 & 5 \\
\hline 20 & 11 & 11 & 10 & 67.1 & 8.6 & 11.4 & 1.4 & 11.4 & 7.221 & 144 & 2.15 \\
\hline 21 & 7 & 7 & 6 & 17.6 & 18.4 & 41.6 & 11.2 & 11.2 & 9.221 & 125 & 1.95 \\
\hline 22 & 7 & 7 & 6 & 27.3 & 16.7 & 37.9 & 10.6 & 7.6 & 4.771 & 66 & 2.11 \\
\hline 23 & 11 & 10 & 8 & 28.8 & 31.8 & 36.4 & 1.5 & 1.5 & 3.402 & 67 & 4.5 \\
\hline 24 & 7 & 7 & 6 & 8.1 & 14.9 & 55.4 & 17.6 & 4.1 & 5.624 & 75 & 1.29 \\
\hline Atenguillo & 24 & 21 & 18 & 29.8 & 18.1 & 36.5 & 8.5 & 7.2 & 6.048 & 95.4 & 2.4 \\
\hline
\end{tabular}

Nevado, Nevado de Colima. Estratos: I, arbustos (2-7 m de altura); II, árboles bajos (8-14 m); III, árboles medianos a altos (15-25 m); $\mathrm{IV}$, árboles altos (26-30 m), y V, emergentes (> $30 \mathrm{~m})$. AB, área basal; D, densidad.

Cuadro 4. Especies por área y sus atributos estructurales, incluyendo sus valores de importancia y el número de individuos por estrato de altura, en bosques de Abies de Jalisco, México

\begin{tabular}{|c|c|c|c|c|c|c|c|c|c|c|c|c|c|c|c|c|c|c|c|}
\hline \multirow{2}{*}{$\begin{array}{c}\text { Cacoma } \\
\text { Acrónimo }\end{array}$} & \multicolumn{14}{|c|}{ Estratos } & \multicolumn{5}{|c|}{ Estratos } \\
\hline & $\mathrm{AB}$ & $\mathrm{D}$ & $\mathrm{F}$ & VI (\%) & I & II & III & IV & $\mathrm{V}$ & Acrónimo & $\mathrm{AB}$ & $\mathrm{D}$ & $\mathrm{F}$ & VI (\%) & I & II & III & IV & $\mathrm{V}$ \\
\hline Abirem & 35.251 & 426 & 40 & 51.65 & 19 & 63 & 106 & 9 & 16 & Pindev & 0.696 & 4 & 1 & 0.86 & 0 & 0 & 1 & 1 & 0 \\
\hline Arbxal & 0.357 & 2 & 1 & 0.57 & 0 & 1 & 0 & 0 & 0 & Pindou & 4.275 & 16 & 5 & 4.62 & 1 & 1 & 5 & 0 & 1 \\
\hline Celpri & 0.003 & 2 & 1 & 0.35 & \multicolumn{5}{|c|}{ Bejuco } & Quecan & 2.317 & 12 & 6 & 3.5 & 0 & 0 & 5 & 0 & 1 \\
\hline Clehar & 0.354 & 2 & 1 & 0.56 & 0 & 0 & 0 & 1 & 0 & Quelau & 0.314 & 2 & 1 & 0.54 & 0 & 1 & 0 & 0 & 0 \\
\hline Cleint & 1.704 & 24 & 7 & 3.95 & 0 & 5 & 7 & 0 & 0 & Quemar & 4.323 & 26 & 10 & 6.39 & 2 & 3 & 7 & 0 & 1 \\
\hline Clefra & 0.254 & 2 & 1 & 0.5 & 0 & 0 & 1 & 0 & 0 & Rhahin & 0.002 & 2 & 1 & 0.35 & 1 & 0 & 0 & 0 & 0 \\
\hline Cordis & 1.208 & 10 & 2 & 1.71 & 2 & 0 & 2 & 0 & 1 & Rumflo & 0.019 & 12 & 3 & 1.34 & 6 & 0 & 0 & 0 & 0 \\
\hline Eupare & 0.004 & 2 & 1 & 0.35 & 1 & 0 & 0 & 0 & 0 & Sarcon & 0.001 & 2 & 1 & 0.35 & 1 & 0 & 0 & 0 & 0 \\
\hline Eupsch & 0.047 & 48 & 12 & 5.34 & 24 & 0 & 0 & 0 & 0 & Solchr & 0.007 & 2 & 1 & 0.35 & 1 & 0 & 0 & 0 & 0 \\
\hline Frauhd & 0.002 & 2 & 1 & 0.35 & 1 & 0 & 0 & 0 & 0 & Symcit & 0.440 & 34 & 8 & 3.9 & 8 & 9 & 0 & 0 & 0 \\
\hline Ilebra & 0.618 & 2 & 1 & 0.72 & 0 & 0 & 1 & 0 & 0 & Terlin & 0.442 & 6 & 3 & 1.31 & 1 & 1 & 1 & 0 & 0 \\
\hline Leasub & 0.022 & 14 & 4 & 1.44 & 7 & 0 & 0 & 0 & 0 & Vitbla & 0.002 & 1 & 1 & 0.35 & \multicolumn{5}{|c|}{ Bejuco } \\
\hline Magilt & 1.663 & 10 & 3 & 2.24 & 0 & 2 & 1 & 0 & 2 & Xylfle & 0.093 & 26 & 9 & 3.57 & 10 & 3 & 0 & 0 & 0 \\
\hline Melden & 0.391 & 6 & 3 & 1.28 & 0 & 3 & 0 & 0 & 0 & Total & 54.880 & 707 & 132 & 100 & 88 & 94 & 137 & 11 & 22 \\
\hline Perhin & 0.071 & 10 & 4 & 1.53 & 3 & 2 & 0 & 0 & 0 & & & & & & & & & & \\
\hline Nevado & \multicolumn{14}{|c|}{ Estratos } & \multicolumn{5}{|c|}{ Estratos } \\
\hline Acrónimo & $\mathrm{AB}$ & $\mathrm{D}$ & $\mathrm{F}$ & VI & I & II & III & IV & $\mathrm{V}$ & Acrónimo & $\mathrm{AB}$ & $\mathrm{D}$ & F & VI (\%) & I & II & III & IV & $\mathrm{V}$ \\
\hline Abirer & 28.913 & 412 & 46 & 56.51 & 63 & 51 & 50 & 24 & 18 & Quelau & 14.874 & 84 & 24 & 22.16 & 20 & 8 & 8 & 3 & 3 \\
\hline Budcor & 0.459 & 4 & 2 & 1.15 & 0 & 0 & 2 & 0 & 0 & Rumflo & 0.021 & 32 & 5 & 3.3 & 16 & 0 & 0 & 0 & 0 \\
\hline Cester & 0.002 & 2 & 1 & 0.42 & 1 & 0 & 0 & 0 & 0 & Salpar & 0.385 & 6 & 3 & 1.51 & 0 & 1 & 2 & 0 & 0 \\
\hline Cordis & 0.010 & 2 & 1 & 0.42 & 0 & 1 & 0 & 0 & 0 & Senang & 0.0152 & 14 & 5 & 2.31 & 7 & 0 & 0 & 0 & 0 \\
\hline Eupmai & 0.005 & 4 & 2 & 0.83 & 2 & 0 & 0 & 0 & 0 & Senbar & 0.002 & 2 & 1 & 0.42 & 1 & 0 & 0 & 0 & 0 \\
\hline Lupsti & 0.014 & 14 & 5 & 2.31 & 7 & 0 & 0 & 0 & 0 & Vibhar & 0.095 & 4 & 2 & 0.9 & 0 & 2 & 0 & 0 & 0 \\
\hline Pindou & 0.094 & 4 & 2 & 0.89 & 0 & 2 & 0 & 0 & 0 & Total & 48.521 & 608 & 109 & 100 & 120 & 67 & 64 & 30 & 23 \\
\hline Pinpse & 3.631 & 24 & 10 & 6.87 & 3 & 2 & 2 & 3 & 2 & & & & & & & & & & \\
\hline Manantlán & \multicolumn{14}{|c|}{ Estratos } & \multicolumn{5}{|c|}{ Estratos } \\
\hline Acrónimo & $\mathrm{AB}$ & $\mathrm{D}$ & $\mathrm{F}$ & VI (\%) & I & II & III & IV & $\mathrm{V}$ & Acrónimo & $\mathrm{AB}$ & $\mathrm{D}$ & F & VI (\%) & I & II & III & IV & V \\
\hline Abirem & 7.472 & 58 & 10 & 8.98 & 0 & 5 & 14 & 3 & 7 & Ostvir & 0.422 & 4 & 2 & 0.87 & 0 & 0 & 2 & 0 & 0 \\
\hline
\end{tabular}


Cuadro 4. Continúa

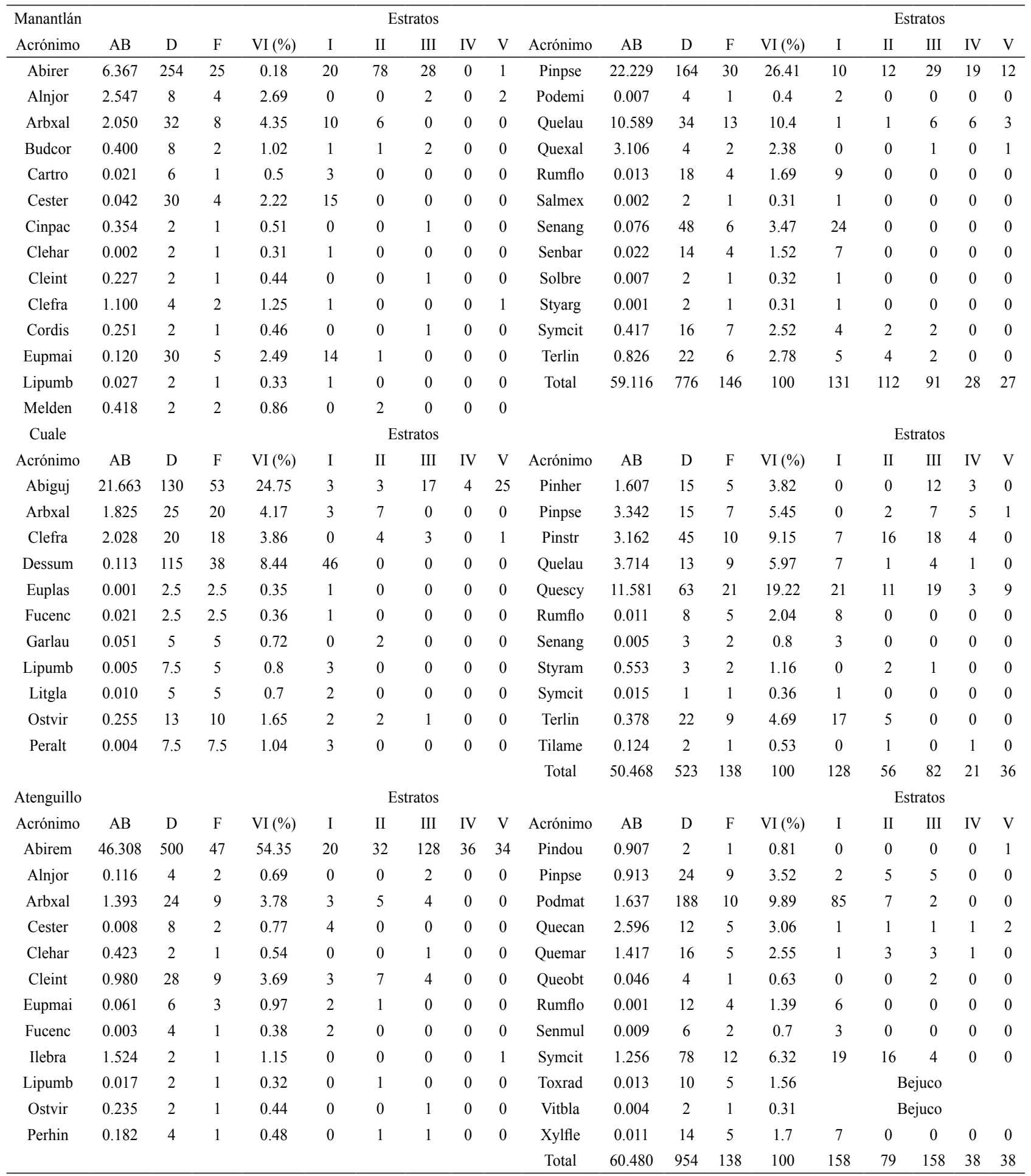

Nevado, Nevado de Colima; AB, área basal, expresada en $\mathrm{m}^{2}$ en 0.5 ha, con excepción de Cuale donde se muestrearon 0.4 ha; D, densidad, expresada como número de individuos en 0.5 ha, con excepción de Cuale; F, frecuencia; VI, valor de importancia. Estratos: I, arbustivo, 2-7 m de altura, II, árboles bajos de 8-14 m; III, medianos a altos de 15-25 m; IV, altos de 26-30 m, y V, emergentes > $30 \mathrm{~m}$. El total por área para AB y D corresponden a $\mathrm{m}^{2}$ y número de individuos llevados a 1 ha. Para el significado de los acrónimos véase el Cuadro 2. 
con una concentración del 54 a $63 \%$ en las categorías de $2.5-20.5 \mathrm{~cm}$, y una disminución muy notoria hacia las categorías diamétricas mayores (Fig. 2).

Riqueza y diversidad. Se registraron 64 especies en toda la superficie muestreada. El número de especies por área osciló entre 14 y 28, consignándose la mayor riqueza para Manantlán, Cacoma y Cuale. No se encontraron diferencias significativas $(\alpha=0.05)$ entre áreas y dentro de ellas, para la riqueza de especies, géneros, familias e índice de Simpson, aunque se observa una tendencia a una menor riqueza y diversidad en el Nevado de Colima (Cuadros 1, 3).

El índice cuantitativo de Sørensen mostró que la similitud entre las parcelas de una misma área varió de 0 al $79 \%$, como ocurrió en la sierra de Manantlán. El índice de similitud promedio mayor se registró para el Nevado de Colima (61\%) y el más bajo en Manantlán (28\%). El índice de similitud promedio mayor fue entre Cacoma y Atenguillo (44\%) y el Nevado de Colima y Manantlán (31\%), superando en los 2 casos los índices promedio de sus propias parcelas. Los más bajos se presentaron entre el Nevado de Colima-Cacoma (1\%), Cacoma-Cuale (2\%), Nevado de Colima-Atenguillo (1\%) y Cuale-Atenguillo (2\%) (Cuadro 5).

No hubo diferencias significativas en la similitud promedio entre parcelas de la misma área, pero sí las hubo entre áreas (Cuadro 6). Entre parcelas, 4 áreas mostraron diferencias significativas y sólo Atenguillo y Cacoma no las tuvieron. Entre parcelas de distintas áreas, las mayores diferencias se dieron entre el Nevado de ColimaAtenguillo, Nevado de Colima-Cacoma, Cacoma-Cuale, Manantlán-Atenguillo y Cuale-Atenguillo (Cuadro 6).

\section{Discusión}

Composición florística. La observación de que Asteraceae, Pinaceae y Fagaceae hayan resultado las familias con más especies coincide con lo registrado para los bosques de Abies por otros autores ( Rzedowski y McVaugh, 1966; Rzedowski, 1978; Sánchez-González y López-Mata, 2003; Velásquez-Villatoro, 2004; Encina-Domínguez et

Cuadro 5. Similitud entre parcelas y entre áreas a través del índice cuantitativo de Sørensen. Los valores arriba de la diagonal corresponden a la similitud entre parcelas de las mismas y diferentes áreas. Los valores por debajo de la diagonal corresponden a los valores promedios de similitud entre las parcelas de la misma área y entre parcelas de las diferentes áreas. Nevado = Nevado de Colima

\begin{tabular}{|c|c|c|c|c|c|c|c|c|c|c|c|c|c|c|c|c|c|c|c|c|c|c|c|c|c|}
\hline & \multicolumn{5}{|c|}{ Cacoma } & \multicolumn{5}{|c|}{ Nevado } & \multicolumn{5}{|c|}{ Manantlán } & \multicolumn{4}{|c|}{ Cuale } & \multicolumn{5}{|c|}{ Atenguillo } \\
\hline & & P1 & P2 & P3 & P4 & P5 & P6 & P7 & P8 & P9 & P10 & P11 & P12 & P13 & P14 & P15 & P16 & P17 & P18 & P19 & P20 & P21 & P22 & P23 & P24 \\
\hline \multirow{5}{*}{ 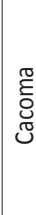 } & P1 & & 0.61 & 0.53 & 0.21 & 0.27 & 0.01 & 0.00 & 0.03 & 0.00 & 0.00 & 0.01 & 0.00 & 0.01 & 0.21 & 0.15 & 0.00 & 0.01 & 0.01 & 0.01 & 0.22 & 0.75 & 0.51 & 0.38 & 0.76 \\
\hline & P2 & & & 0.58 & 0.25 & 0.30 & 0.01 & 0.00 & 0.00 & 0.00 & 0.00 & 0.01 & 0.00 & 0.01 & 0.24 & 0.17 & 0.00 & 0.01 & 0.01 & 0.01 & 0.28 & 0.51 & 0.56 & 0.56 & 0.70 \\
\hline & P3 & & & & 0.46 & 0.39 & 0.00 & 0.01 & 0.02 & 0.05 & 0.00 & 0.02 & 0.00 & 0.01 & 0.30 & 0.30 & 0.07 & 0.03 & 0.05 & 0.02 & 0.30 & 0.46 & 0.65 & 0.58 & 0.59 \\
\hline & P4 & & & 0.39 & & 0.36 & 0.02 & 0.03 & 0.01 & 0.06 & 0.01 & 0.01 & 0.01 & 0.01 & 0.33 & 0.28 & 0.05 & 0.02 & 0.04 & 0.01 & 0.15 & 0.28 & 0.30 & 0.51 & 0.40 \\
\hline & P5 & & & & & & 0.00 & 0.00 & 0.00 & 0.00 & 0.00 & 0.02 & 0.00 & 0.02 & 0.43 & 0.24 & 0.03 & 0.00 & 0.02 & 0.01 & 0.21 & 0.23 & 0.39 & 0.39 & 0.35 \\
\hline \multirow{5}{*}{ z } & P6 & & & & & & & 0.44 & 0.61 & 0.45 & 0.65 & 0.43 & 0.40 & 0.43 & 0.17 & 0.03 & 0.00 & 0.07 & 0.13 & 0.04 & 0.00 & 0.00 & 0.07 & 0.02 & 0.00 \\
\hline & P7 & & & & & & & & 0.58 & 0.59 & 0.69 & 0.76 & 0.35 & 0.69 & 0.09 & 0.10 & 0.03 & 0.01 & 0.06 & 0.05 & 0.01 & 0.00 & 0.00 & 0.01 & 0.04 \\
\hline & P8 & & & 0.01 & & & & & & 0.70 & 0.69 & 0.09 & 0.38 & 0.09 & 0.06 & 0.03 & 0.08 & 0.08 & 0.09 & 0.01 & 0.00 & 0.01 & 0.02 & 0.00 & 0.02 \\
\hline & P9 & & & & & & & & 0.61 & & 0.59 & 0.48 & 0.39 & 0.57 & 0.13 & 0.20 & 0.12 & 0.05 & 0.10 & 0.02 & 0.00 & 0.00 & 0.05 & 0.03 & \begin{tabular}{|l|l|} 
\\
\end{tabular} \\
\hline & P10 & & & & & & & & & & & 0.67 & 0.29 & 0.69 & 0.06 & \begin{tabular}{|l|l|}
0.04 \\
\end{tabular} & 0.00 & 0.06 & 0.02 & 0.00 & 0.00 & 0.00 & 0.01 & 0.00 & 0.00 \\
\hline \multirow{5}{*}{$\sum^{\pi}$} & P11 & & & & & & & & & & & & 0.23 & 0.79 & 0.19 & 0.07 & 0.03 & 0.08 & 0.10 & 0.20 & 0.01 & 0.11 & 0.12 & 0.00 & 0.00 \\
\hline & P12 & & & & & & & & & & & & & 0.5 & 0.00 & 0.11 & 0.02 & 0.03 & 0.07 & 0.16 & 0.00 & 0.00 & 0.15 & 0.00 & 0.00 \\
\hline & P13 & & & 0.11 & & & & & 0.31 & & & & 0.28 & & 0.20 & 0.08 & 0.04 & 0.10 & 0.13 & 0.21 & 0.01 & 0.06 & 0.13 & 0.00 & 0.04 \\
\hline & P14 & & & & & & & & & & & & & & & 0.46 & 0.04 & 0.08 & 0.07 & 0.14 & 0.19 & 0.23 & 0.52 & 0.35 & 0.30 \\
\hline & P15 & & & & & & & & & & & & & & & & 0.21 & 0.05 & 0.15 & 0.07 & 0.17 & 0.17 & 0.33 & 0.27 & 0.22 \\
\hline \multirow{4}{*}{$\frac{\frac{0}{\sigma 0}}{3}$} & P16 & & & & & & & & & & & & & & & & & 0.58 & 0.36 & 0.36 & 0.01 & 0.02 & 0.02 & 0.00 & 0.00 \\
\hline & P17 & & & 0.02 & & & & & 0.05 & & & & 0.10 & & & & 0.37 & & 0.48 & 0.31 & 0.01 & 0.00 & 0.00 & 0.00 & 0.00 \\
\hline & P18 & & & & & & & & & & & & & & & & & & & 0.28 & 0.03 & 0.03 & 0.03 & 0.00 & 0.01 \\
\hline & P19 & & & & & & & & & & & & & & & & & & & & 0.02 & 0.05 & 0.12 & 0.01 & \begin{tabular}{|l|l|}
0.03 \\
\end{tabular} \\
\hline \multirow{5}{*}{ 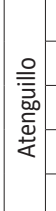 } & P20 & & & & & & & & & & & & & & & & & & & & & 0.22 & 0.28 & 0.33 & 0.26 \\
\hline & P21 & & & & & & & & & & & & & & & & & & & & & & 0.52 & 0.39 & 0.66 \\
\hline & P22 & & & 0.44 & & & & & 0.01 & & & & 0.13 & & & & 0.02 & & & & & 0.46 & & 0.51 & 0.68 \\
\hline & P23 & & & & & & & & & & & & & & & & & & & & & & & & 0.44 \\
\hline & P24 & & & & & & & & & & & & & & & & & & & & & & & & \\
\hline
\end{tabular}




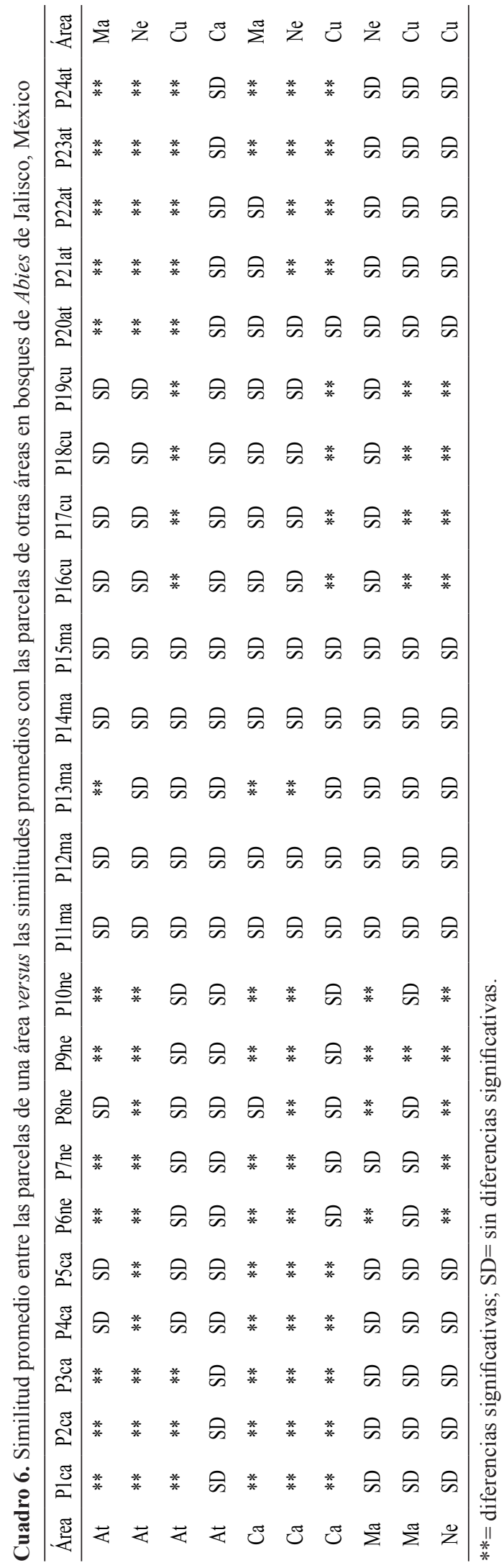

al., 2008), y muy posiblemente se deba a que son grupos taxonómicos que han desarrollado mecanismos morfológicos, anatómicos y fisiológicos que les permiten tolerar las heladas frecuentes que se presentan en algunos meses (Rzedowski, 1978). Esto también podría explicar la diversidad que presentaron Abies, Quercus, Pinus, Eupatorium, los 3 últimos con una amplia adaptabilidad ecológica y una radiación extraordinaria en México (Nixon, 1998; Styles, 1998; Rzedowski, 1998).

La mayoría de los géneros registrados en las áreas de estudio son comunes en los oyametales de otras áreas de México (Sánchez-González et al., 2004), pero por lo que se refiere a las especies, hay varias que sólo se conocen del occidente de México, son disyuntas o presentan su límite de distribución norte o sur en estas áreas de Jalisco, como Abies religiosa var. emarginata, A. guatemalensis var. jaliscana, Clethra fragrans, Pinus strobiformis, Sarcococca conzattii, Eupatorium lasioneurum, Podocarpus matudae y Perymenium alticola (Cuadro 2), lo que podría atribuirse a la distribución insular de estos bosques que, si bien, tuvieron un antecesor común, lo cual se manifiesta por los géneros que comparten, tienen marcadas diferencias en el nivel específico, posiblemente producto de las diversas fuerzas de selección y especiación a las que los grupos taxonómicos han estado sometidos.

El registro en las áreas de estudio de Ilex brandegeana, Carpinus tropicalis, Ostrya virginiana, Cornus disciflora, Persea hintonii, Magnolia iltisiana, entre otras especies (Cuadro 2), es el resultado de las bajas altitudes a las que descienden los Abies en el occidente de México y las mezclas que forman con el bosque mesófilo de montaña, lo cual ocasionó que en algunas parcelas estudiadas (Cuadro 3) la riqueza de especies haya estado por arriba de lo registrado en los oyametales de altitudes superiores a los 3000 metros en otras regiones de México.

La escasez de bejucos en los oyametales estudiados es un patrón compartido con otras investigaciones en las que se señala que es poca la riqueza de bejucos en estos bosques (Rzedowski, 1978; Jiménez, 2004; VelásquezVillatoro, 2004).

Estructura vertical. Las alturas del dosel registradas en las áreas estudiadas, entre 20 y $40 \mathrm{~m}$, con individuos que pueden alcanzar hasta $50 \mathrm{~m}$ o más, coincide con lo que otros autores han encontrado (Rzedowski y McVaugh, 1966; Rzedowski, 1978; Cornejo-Tenorio et al., 2003; Jiménez, 2004), así también los géneros de las especies que forman parte del dosel, como Pinus, Quercus, Clethra, Arbutus, Meliosma, Salix, Ilex, Magnolia y Podocarpus (Rzedowski y McVaugh, 1966; Rzedowski, 1978; RamosHerrera, 1991; Figueroa-Rangel y Moreno-Gómez, 1993; Jiménez, 2004). La concentración de más del 55\% de los individuos con alturas entre 2 y $14 \mathrm{~m}$ podría deberse a que 
diversas de las especies registradas corresponden biológicamente a taxones de bajo porte y a que varios individuos de las especies del estrato de árboles altos y emergentes presentaban diferentes estadios de desarrollo, algunos en condición juvenil. Este resultado podría interpretarse como un indicio de que las comunidades estudiadas corresponden a bosques que han estado sujetos a aprovechamiento forestal o algún otro factor de perturbación (así manifiesto por la presencia de tocones, pastoreo, incendios; Cuadro 1), y lo que reflejan es capacidad de repoblación por medio de la reincorporación de juveniles.

El promedio de altura y el porcentaje de individuos que en los diferentes estratos fue casi igual en las 5 áreas estudiadas podría deberse a que el manejo o los factores de perturbación que han estado operando sobre estas comunidades han sido parecidos, aunque en todas las áreas los bosques mostraron una buena capacidad de recuperación, la cual podrían estar favoreciendo las declaratorias de áreas naturales protegidas en las últimas 2 o 3 décadas y la protección a las especies de Abies en la NOM-059SEMARNAT-2010 (SEMARNAT, 2010).

Estructura cuantitativa. Las densidades promedio registradas por 0.1 ha para las áreas de estudio y llevada a 1 ha, varió de 608 a 954 individuos con dap $\geq 2.5 \mathrm{~cm}$ (Cuadro 3), cifras que están por abajo de lo que consignan Jiménez (2004) y Encina-Domínguez et al. (2008), quienes midieron plantas con dap a partir de $1 \mathrm{~cm}$ y $5 \mathrm{~cm}$, respectivamente. La densidad registrada está por arriba de lo que encontró Manzanilla (1974), aunque este autor midió especies con dap $\geq 10 \mathrm{~cm}$. El área basal promedio por 0.1 ha y extrapolada a 1 ha varió de 49 a $60 \mathrm{~m}^{2}$, cifra inferior a la registrada por Jiménez (2004) para los bosques de Abies hickelii en Oaxaca y de dimensiones comparables para los bosques naturales y con explotación, y menor a la que obtuvo Manzanilla (1974) para los bosques vírgenes, aunque superior a lo registrado por Encina-Domínguez et al. (2008) para los bosques de Zapalinamé, Coahuila.

Abies religiosa var. emarginata, A. religiosa var. religiosa, Pinus pseudostrobus, Podocarpus matudae, Quercus laurina, Symplocos citrea, Q. scytophylla y A. guatemalensis var. jaliscana presentaron las mayores densidades, áreas basales y valores de importancia (Cuadro 4). Las especies registradas coinciden en general con los mayores atributos estructurales de otras investigaciones en este tipo de vegetación (Ramos-Herrera, 1991; Figueroa-Rangel y Moreno-Gómez, 1993; Ávila-Bello y López-Mata, 2001; Jiménez, 2004). Seguramente la predominancia de estas especies tiene que ver con su historia de vida que les ha permitido desplegar mecanismos fisiológicos, anatómicos y morfológicos para establecerse y desarrollarse en ambientes de alta montaña.
La ausencia de diferencias significativas en las variables área basal y densidad, entre áreas y parcelas dentro de cada área, es un indicador de la similitud estructural que presentan los bosques estudiados. Esta similitud se reafirma por las estructuras diamétricas de las comunidades de cada área, las cuales fueron muy similares con una concentración entre el 54 y $63 \%$ en categorías entre 2.5 y $20.5 \mathrm{~cm}$ (Fig. 2), lo cual se considera un patrón típico de comunidades que están en proceso de recuperación (Jardel-Peláez, 1986; Figueroa-Rangel y Olvera-Vargas, 2000) y se acentúa aún más por la presencia de especies que biológicamente son de porte pequeño y quedan incluidas en estas categorías diamétricas.

Riqueza y diversidad. Las 64 especies, representantes de 47 géneros y 35 familias, de individuos con dap $\geq 2.5 \mathrm{~cm}$, registradas en las parcelas de muestreo, supera al número de taxones consignados en otras investigaciones para los bosques de oyamel (Nieto de Pascual-Pola, 1995; Sánchez-González y López-Mata, 2003; Velásquez-Villatoro, 2004; Jiménez, 2004). El número de especies registradas por parcela de 0.1 ha en las 5 áreas estudiadas fue de 4-20 especies, lo cual queda dentro de las amplitudes registradas en otras investigaciones para superficies de 0.1 ha, no obstante que difieren los diámetros a la altura del pecho a partir de los cuales se consideran los individuos (Velásquez-Villatoro, 2004).

Aunque no se encontraron diferencias significativas respecto a la riqueza de especies y la diversidad entre áreas y parcelas dentro de las áreas, el Nevado de Colima presentó una tendencia a disminuir el número de especies y su diversidad, lo cual podría estar reflejando un gradiente de altitud, temperatura y humedad, pues es en esta área donde se han registrado las temperaturas mínimas extremas más bajas, mayor radiación potencial, menor humedad disponible y en general la mayor perturbación (Cuevas-Guzmán et al., 2008; Cuadro 1). Se ha registrado que algunos de estos factores son de mucha importancia en la disminución de la riqueza y la diversidad de especies (Rzedowski, 1978; Vázquez-García y Givnish, 1998; Körner, 2002).

La razón por la cual el índice de similitud cuantitativo de Sørensen es más alto en la zona de Manantlán podría atribuirse a que las parcelas se establecieron a lo largo de una mayor amplitud altitudinal, lo que genera mayor heterogeneidad ambiental que se expresa en similitudes altas entre parcelas que comparten más o menos las mismas condiciones ambientales, y bajas entre las que contrastan, como ocurrió entre las parcelas 11,12 y 13 y las parcelas 14 y 15 (Cuadro 5). Las parcelas 14 y 15 se localizan a $2450 \mathrm{~m}$ de altitud, donde los Abies se encuentran mezclados con especies latifoliadas, mientras que las parcelas $11-13$ se ubican a mayor altitud en la sierra de Manantlán, entre 2700 y 2750 $\mathrm{m}$, donde los oyametales tienden a ser más monoespecíficos. 
También podría ser ésta la causa de que Manantlán presente el índice de similitud promedio más bajo.

La razón por la cual el Nevado de Colima registró el índice de similitud promedio más alto se atribuye a la baja heterogeneidad ambiental que presentan los bosques de oyamel en esta área, lo que se manifiesta en una baja variación en la composición de especies y su abundancia. El índice de similitud promedio mayor fue para Cacoma y Atenguillo (44\%) (Cuadro 5), y fueron las únicas áreas que no mostraron diferencias significativas entre las similitudes promedio de sus parcelas. Este resultado podría atribuirse a su cercanía y a que son parte de la misma sierra que forma un continuo, con gradientes ambientales con menos variación dentro de ellas, respecto a las otras áreas estudiadas. Las similitudes

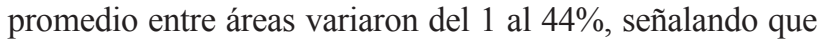
el número de especies compartidas en los bosques de Abies de las áreas muestreadas es bajo, lo cual se corrobora con las comparaciones de las similitudes promedio entre las parcelas de las 5 áreas, ya que en todas hubo diferencias significativas $(\alpha=0.05)$, con excepción de Cacoma y Atenguillo (Cuadro 6). Las mayores diferencias del área del Nevado de Colima con las otras 4 y mayor similitud con Manantlán es un patrón que ya había sido registrado por Cuevas-Guzmán et al. (2008) a través de una clasificación en la cual un grupo de oyametales de Manantlán se agrupó con el Nevado de Colima y otro con Cacoma y Atenguillo, mientras que el Nevado de Colima quedó muy separado de Cacoma, Atenguillo y Cuale.

Conclusiones y recomendaciones. Los bosques de oyamel de las 5 áreas estudiadas en el estado de Jalisco fueron similares en su estructura, riqueza y diversidad. En las 5 áreas las comunidades mostraron una concentración de individuos jóvenes en categorías diamétricas y alturas pequeñas; este patrón permite deducir un proceso de recuperación de las especies de los estratos de árboles altos y emergentes. Los incidentes de perturbaciones que se manifiestan en todas las áreas por el hallazgo de tocones, árboles caídos, rastros de incendios y ganadería, testifican el uso de que son y han sido objeto estas comunidades vegetales, las cuales por su repoblación en todas las áreas muestran buena capacidad de recuperación.

Las diferencias en la similitud promedio entre áreas son indicativas de la alta diversidad beta de los bosques de Abies en el estado de Jalisco, pues 4 áreas muestran diferencias estadísticas significativas y sólo Cuale y Atenguillo mostraron una composición florística similar.

Los bosques de oyamel de Jalisco, por la distribución insular que presentan, los factores de perturbación a que han estado sometidos y el efecto esperado del cambio climático sobre ellos, demandan de un monitoreo continuo que garantice la generación de alternativas para su conservación.
Los bosques de oyamel debieran ser decretados áreas de conservación y de recarga de mantos acuíferos y su manejo debiera ser única y exclusivamente aquel que garantice la integridad del ecosistema y mantenga la diversidad beta.

\section{Agradecimientos}

Esta investigación fue respaldada económicamente a través del fondo de investigación del Centro Universitario de la Costa Sur de la Universidad de Guadalajara. El segundo autor recibió aportación económica mediante una beca otorgada por el Programa de Apoyo a la Investigación de la Universidad de Guadalajara para miembros del Sistema Nacional de Investigadores. Se reconoce el apoyo de campo proporcionado por Francisco J. Santana Michel y Germán Guzmán Sánchez; la elaboración del mapa de la zona de estudio a Demetrio Meza, y la traducción del resumen al inglés a Carlos Palomera García. Dos revisores anónimos proporcionaron recomendaciones y sugerencias que mejoraron sustancialmente el artículo.

\section{Literatura citada}

Alvarado, R. D., L. I. de Bauer y J. Galindo. 1991. Declinación y muerte del bosque de oyamel (Abies religiosa) en el sur del Valle de México. Agrociencia 3:123-143.

Ávila-Bello, C. H., J. Aguirre-Rivera y E. García-Moya. 1994. Variación estructural del bosque de Abies hickelii Flous \& Gaussen en relación con factores ambientales en el Pico de Orizaba, México. Investigación Agraria, Sistemas y Recursos Forestales 3:5-17.

Ávila-Bello, C. H. y L. López-Mata. 2001. Distribución y análisis estructural de Abies hickelii Flous \& Gaussen en México. Interciencia 26:244-251.

Calvert, W. H. y R. O. Lawton. 1993. Comparative phenology of variation in size, weight, and water content of eastern North American monarch butterflies at five overwintering sites in Mexico. In Biology and conservation of the monarch butterfly, S. B. Malcolm and M. P. Zalucki. (eds.). Los Ángeles, California. p. 299-307.

Cornejo-Tenorio, G., A. Casas, B. Farfán, J. L. Villaseñor y G. Ibarra-Manríquez. 2003. Flora y vegetación de las zonas núcleo de la Reserva de la Biosfera Mariposa Monarca, México. Boletín de la Sociedad Botánica de México 73:4362.

Cuevas-Guzmán, R. 2002. Análisis de gradientes de la vegetación de la cañada El Tecolote, en la sierra de Manantlán, Jalisco, México. Tesis, doctorado Colegio de Postgraduados, Montecillo, Estado de México. 140 p.

Cuevas-Guzmán, R., L. M. Martínez-Rivera, A. Cisneros-Lepe, E. V. Sánchez-Rodríguez y L. Guzmán-Hernández. 2008. Ordenación y clasificación de los oyametales del estado de 
Jalisco, México. In Ecología, manejo y conservación de los ecosistemas de montaña en México, L. R. Sánchez, J. Galindo y F. Díaz (eds.). Mundi-Prensa, México, D. F. p. 212-227.

Curtis, J. T. y R. P. McIntosh. 1951. An upland forest continuum in the prairie forest border region of Wisconsin. Ecology 32:476-496.

Earle, J. C. 2002. Abies (Plin. Ex Tourn.) Miller 1754. Disponible en: http://www.conifers.org/pi/ab/index.htm; última consulta 07.VII.2002.

Encina-Domínguez, J. A., F. J. Encina-Domínguez, E. MataRocha y J. Valdés-Reyna. 2008. Aspectos estructurales, composición florística y caracterización ecológica del bosque de oyamel de la sierra de Zapalinamé, Coahuila, México. Boletín de la Sociedad Botánica de México 83:13-24.

Fagre, D. y D. L. Peterson. 2002. Modelling and monitoring ecosystem responses to climate chance in three North American mountain ranges. In Mountain biodiversity a global assessment, C. Körner y E. M. Spehn (eds.). Parthenon, New York. p. 249-259.

Figueroa-Rangel, B. L. 1991. Estructura y distribución de las poblaciones de Abies spp., en cerro Grande, México. Tesis, Facultad de Ciencias Biológicas, Universidad de Guadalajara, Jalisco. 90 p.

Figueroa-Rangel, B. L. y S. Moreno-Gómez. 1993. Estructura y sucesión en poblaciones de Abies religiosa (H.B.K.) Schlecht. et Cham., y Abies religiosa var. emarginata Loock et Martínez ex Martínez, en la sierra de Manantlán, Jalisco. Agrociencia 3:49-63.

Figueroa-Rangel, B. L. y M. Olvera-Vargas. 2000. Dinámica de la composición de especies en bosques de Quercus crassipes Humb. \& Bonpl., en Cerro Grande, Sierra de Manantlán, México. Agrociencia 34:91-98.

Fulé, P. Z. y W. W. Covington. 1997. Fire regimes and forest structure in the sierra Madre Occidental, Durango, México. Acta Botanica Mexicana 41:43-79.

Jardel-Peláez, E. J. 1986. Efecto de la explotación forestal en la estructura y regeneración del bosque de coníferas de la vertiente oriental del Cofre de Perote, Veracruz, México. Biotica 11:247-270.

Jiménez R., J. L. 2004. Estructura del bosque de Abies hickelii Flous \& Gaussen en Santa María Yavesía, Distrito de Ixtlán, Oaxaca, México. Tesis, Facultad de Ciencias, Universidad Nacional Autónoma de México, México, D. F. 74 p.

Körner, C. 2002. Mountain biodiversity, its causes and function: an Overview. In Mountain biodiversity a global assessment, Ch. Körner y E. M. Spehn (eds.) Parthenon, New York. p.3-20.

López, M. A., J. Velázquez, A. V. González y V. M. Cetina. 1998. Estado nutrimental de Abies religiosa en un área con problemas de contaminación ambiental. Agrociencia 32:53-59.

Madrigal-Sánchez, X. 1967. Contribución al conocimiento de la ecología de los bosques de oyamel [Abies religiosa (H.B.K.) Schlecht. \& Cham] en el Valle de México. Boletín Técnico 18. Instituto Nacional de Investigaciones Forestales, México, D. F. 94 p.

Magurran, A. E. 2004. Measuring biological diversity. Blackwell, Oxford. 256 p.

Manzanilla, H. 1974. Investigaciones epidométricas y silvícolas en bosques mexicanos de Abies religiosa. Dirección General de Información y Relaciones Públicas, Secretaría de Agricultura y Ganadería. México, D. F. 165 p.

Martínez, M. 1963. Las pináceas mexicanas, tercera edición. Universidad Nacional Autónoma de México, México, D. F. $400 \mathrm{p}$.

McCune, B. y M. J. Mefford. 1999. PC-ORD. Multivariate analysis of ecological data, Ver. 4. MjM Software Design, Gleneden Beach, Oregon. 237 p.

McVaugh, R. 1992. Gymnosperms and Pterydophytes. Flora Novo-Galiciana 17:467 p.

Nieto de Pascual-Pola, C., L. I. Zamora-Martínez y M. C. Zamora. 1995. Estudio monográfico del género Abies en México. Libro de resúmenes del XIII Congreso Mexicano de Botánica. Universidad Autónoma del Estado de Morelos y Sociedad Botánica de México, del 5 al 11 de noviembre de 1995. Cuernavaca, Morelos. p. 160.

Nieto de Pascual-Pola, C. 1995. Estudio sinecológico del bosque de oyamel de la cañada de Contreras, Distrito Federal. Revista Ciencia Forestal en México 77:3-34.

Nixon, K. C. 1998. El género Quercus en México. In Diversidad biológica de México: orígenes y distribución, T. P. Ramamoorthy, R. Bye, A. Lot y J. Fa (comp.). Universidad Nacional Autónoma de México. México, D. F. p. 433-447.

Olvera-Vargas, M., S. Moreno-Gómez y B. L. Figueroa-Rangel. 1996. Sitios permanentes para la investigación silvícola. Universidad de Guadalajara, Jalisco. 60 p.

PRODEFO (Programa de Desarrollo Forestal de Jalisco). 1999. Superficie de recursos forestales del estado de Jalisco (según región COPLADE, Municipio y Área Natural de Conservación). Programa de Desarrollo Forestal de Jalisco, Guadalajara. 158 p.

Ramos-Herrera, M. J. 1991. Estudio de la distribución del género Abies en la Sierra de Manantlán, Jalisco. Tesis, Facultad de Ciencias Biológicas, Universidad de Guadalajara. Guadalajara, Jalisco. 102 p.

Rendón, S. E. 1997. Diagnóstico de las mariposas monarca hibernantes que intentaron alimentarse y la estructura del rodal del bosque donde se agrupó la colonia del Llano del Toro en la sierra Chincua, Mich., durante la temporada de hibernación 1993-1994. Tesis profesional, Facultad de Ciencias, Universidad Nacional Autónoma de México. México, D. F. 54 p.

Rzedowski, J. 1998. Diversidad y orígenes de la flora fanerogámica de México. In Diversidad biológica de México: 
orígenes y distribución, T. P. Ramamoorthy, R. Bye, A. Lot y J. Fa (eds.). Instituto de Biología, UNAM, México, D. F. p. 129-145.

Rzedowski, J. 1978. Vegetación de México. Limusa. México, D. F. $432 \mathrm{p}$

Rzedowski, J. y R. McVaugh. 1966. La vegetación de Nueva Galicia. Contributions from the University of Michigan Herbarium 9: 1-123.

SEMARNAT (Secretaría de Medio Ambiente, Recursos Naturales y de Pesca). 2010. Norma Oficial Mexicana NOM-059SEMARNAT-2010, Protección ambiental-Especies nativas de México de flora y fauna silvestres-Categorías de riesgo y especificaciones para su inclusión, exclusión o cambioLista de especies en riesgo. Diario Oficial de la Federación., Segunda sección, 30 de diciembre, México, D. F. 77 p.

Saavedra-Romero, L. de L., D. Alvarado-Rosales, J. VargasHernández y T. Hernández-Tejeda. 2003. Análisis de la precipitación pluvial en bosques de Abies religiosa (H.B.K.) Schltdl. \& Cham., en el sur de la ciudad de México. Agrociencia 37:57-64.

Sánchez-Gónzalez, A. 2004. Análisis sinecológico, florístico y biogeográfico de la vegetación del norte de la sierra Nevada, México. Tesis, doctorado Colegio de Posgraduados, Montecillo, Estado de México. 153 p.

Sánchez-González, A. y L. López-Mata. 2003. Clasificación y ordenación de la vegetación del norte de la sierra Nevada, a lo largo de un gradiente altitudinal. Anales del Instituto de Biología, Universidad Nacional Autónoma de México, Serie Botánica 74:47-71.

Sánchez-González, A., L. López-Mata y D. Granados-Sánchez. 2004. Semejanza florística entre los bosques de Abies religiosa (H.B.K.) Cham. y Schltdl. de la Faja Volcánica Transmexicana. Investigaciones Geográficas, Boletín del Instituto de Geografía 56:62-76.
Sánchez-Velásquez, L. R., M. R. Pineda-López y A. HernándezMartínez. 1991. Distribución y estructura de la población de Abies religiosa (H.B.K.) Schlecht. \& Cham., en el Cofre de Perote, estado de Veracruz, México. Acta Botanica Mexicana 16:45-55.

SAS Institute. 1999. SAS/STAT User's Guide, Release 8.0 edition, SAS Institute, Cary, Carolina del Norte. 3884 p.

Styles, B. T. 1998. El género Pinus: su panorama en México. In Diversidad biológica de México: orígenes y distribución, T. P. Ramamoorthy, R. Bye, A. Lot y J. Fa (comp.). Instituto de Biología, Universidad Nacional Autónoma de México, México, D. F. p. 385-408.

UAAAN (Universidad Autónoma Agraria Antonio Narro). 2002. Restauración ambiental de la sierra Plegada de Coahuila. Informe técnico. Comisión Federal de Electricidad/ Secretaría de Medio Ambiente y Recursos Naturales/ Universidad Autónoma Agraria Antonio Narro/ Laboratorio de Sistemas de Información Geográfica, UAAAN, Saltillo, Coahuila.

Vázquez, J. A. y T. Givnish. 1998. Altitudinal gradients in tropical forest composition, structure, and diversity in the Sierra de Manantlán. Journal of Ecology 86: 999-1020.

Velásquez-Villatoro, M. 2004. La sucesión ecológica una opción para recuperaráreas de pinabete (Abies guatemalensis Rehder) en Guatemala. Memorias del Simposio Internacional sobre Restauración Ecológica. Grupo Cubano de Restauración Ecológica, Empresa Nacional para la Protección del la Flora y la Fauna, Jardín Botánico de Villa Clara, del 17-21 de noviembre de 2004. Cuba. [Formato en CD].

Villers-Ruíz, L., L. García del Valle y J. López-Blanco. 1998. Evaluación de los bosques templados de México: una aplicación en el Parque Nacional Nevado de Toluca. Investigaciones Geográficas, Boletín del Instituto de Geografía 36:7-19. 